\title{
Cystic fibrosis: current survival and population estimates to the year 2000
}

\author{
J S Elborn, D J Shale, J R Britton
}

\begin{abstract}
Background Survival from cystic fibrosis is increasing rapidly. Estimates of the extent of this improvement should allow health care facilities to be planned to deal with the expanding population of patients with cystic fibrosis. Estimates of life expectancy are also essential if accurate information on current prognosis is to be given to parents of an affected child, or to prospective parents deciding whether to proceed with a pregnancy where the fetus may be affected. Methods Survival trends in the national data on cystic fibrosis have been analysed to produce estimates of the likely size of the cystic fibrosis population over the next decade and to predict the life expectancy of children born with cystic fibrosis in the years up to 1990.

Results In England and Wales the estimated number of patients with cystic fibrosis is at present about 5200, of whom $3300(63 \%)$ are aged under 16 years. By the year 2000 the total population will increase to 6000 , with $3400(57 \%)$ aged under 16. Thus the number of children with cystic fibrosis will remain fairly constant over the next 10 years, whereas adult numbers will increase by about $36 \%$ (from 1901 to 2577). The median life expectancy of children with cystic fibrosis born in 1990 is estimated to be 40 years, double that of 20 years ago.

Conclusion This study suggests that health service provision for children will not need to change substantially over the next 10 years whereas services for adults will need to increase by about a third. Parents can be counselled that the median life expectancy of a newborn child with cystic fibrosis is currently likely to be of the order of $\mathbf{4 0}$ years.
\end{abstract}

The prognosis for patients with cystic fibrosis has improved substantially over the past four decades. ${ }^{12}$ The improved survival has been attributed to several factors, including earlier diagnosis, ${ }^{2}$ improved management of meconium ileus, ${ }^{3}$ better dietary management and pancreatic enzyme supplementation, ${ }^{24}$ routine physiotherapy, ${ }^{5}$ the development of potent antipseudomonal antibiotics, ${ }^{6}$ and the emergence of specialist treatment centres. ${ }^{27}$ The relative importance of these treatments remains uncertain, ${ }^{2}$ though most patients with cystic fibrosis now receive extensive medical and paramedical support, often with repeated admissions to hospital. ${ }^{238}$ As the cystic fibrosis population expands medical facilities will have to increase to cope with their requirements. To provide estimates of the likely extent of the increase in numbers of patients with cystic fibrosis we have used mortality data for England and Wales to predict the likely trend in survival over the next decade, and to produce estimates of the size and age distribution of the cystic fibrosis population.

Another important aspect of the management of cystic fibrosis is the counselling of parents of affected children at the time of diagnosis. ${ }^{9}$ The recent development of accurate prenatal diagnostic methods for cystic fibrosis $^{10-12}$ is also likely to lead to a rapid increase in the numbers of parents seeking advice on whether to abort an affected fetus. ${ }^{11}{ }^{13}$ In both of these circumstances accurate data on survival prospects are required, and are currently not available. We have therefore used our data predications to estimate the likely life expectancy of children born with cystic fibrosis in England and Wales up to the present day.

\section{Methods}

Mortality data for cystic fibrosis in England and Wales from 1959 to 1986 were obtained from the Office of Population, Censuses, and Surveys. ${ }^{14}$ The number of children born with cystic fibrosis each year was estimated from the total recorded live births, ${ }^{1516}$ on the assumption that one infant in 2500 is homozygous for cystic fibrosis. ${ }^{17} \mathrm{We}$ combined these estimates to produce life tables and annual mortality rates for cystic fibrosis for each year of birth cohort from 1959 to 1986, using the Statistical Package for the Social Sciences (SPSS-X) ${ }^{18}$ Predictions of survival up to the year 2000 were derived by logistic and least squares regression, the generalised linear interactive modelling package (GLIM) being used. ${ }^{19}$

In all birth cohorts mortality was much higher in the first year of life than in subsequent years, though first year mortality improved substantially during the study period (fig 1A). Mortality after the first year was relatively constant within birth cohorts. First year mortality was therefore analysed and predicted separately from subsequent mortality. A logistic regression equation, $y=a x+b$, was fitted to the proportion of affected children dying from cystic fibrosis in the first year of life for each birth cohort from 1959 to 1986, where $y$ represents the logit of the proportion of deaths in any year, $x$ the year, $a$ the logistic gradient 

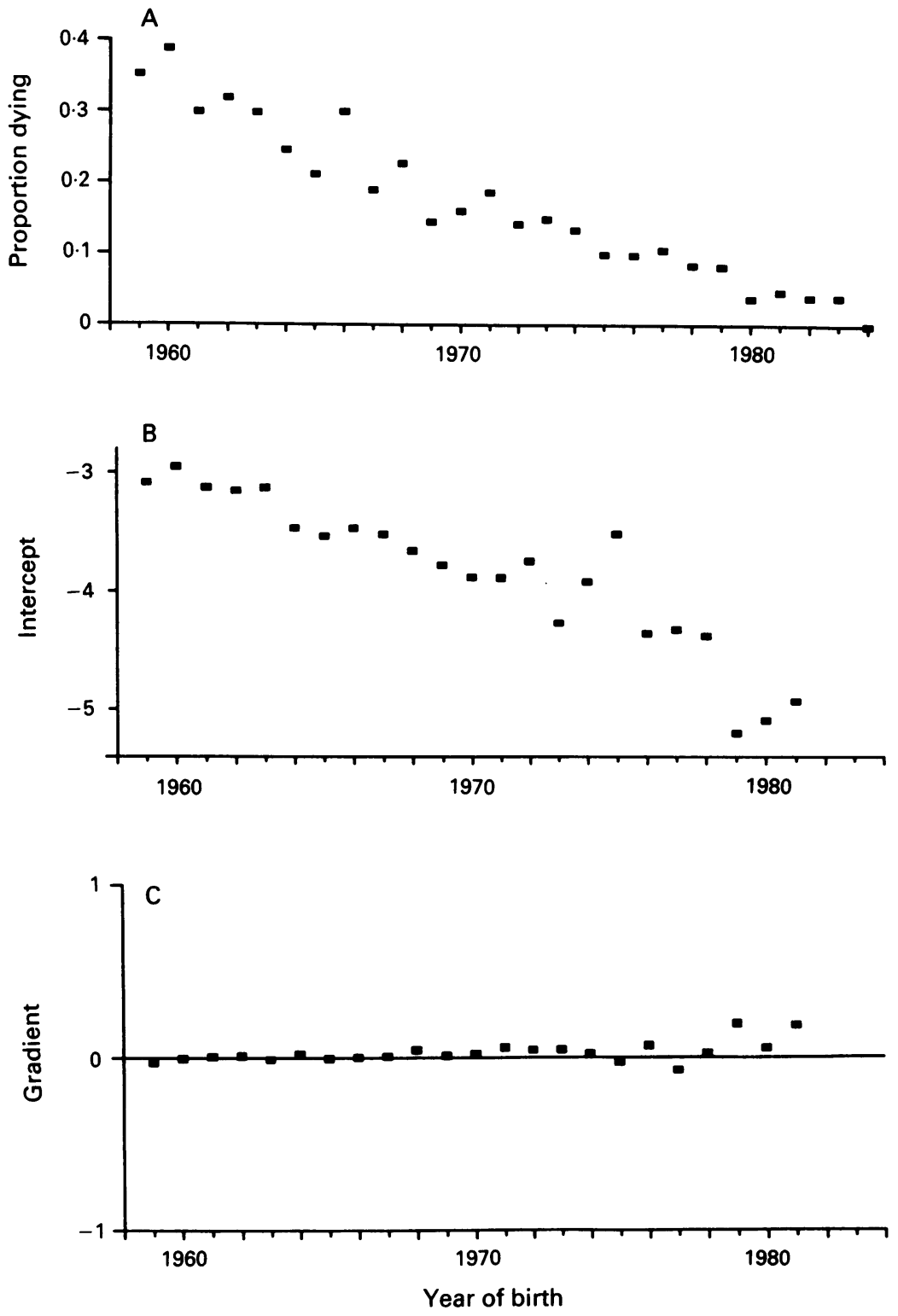

Figure $1 A$-Proportion of live births with cystic fibrosis dying in the first year of life; $B$-logistic intercepts;

C-logistic gradients for the model fitted to survival after the first year of life within year of birth cohorts born from 1959 to 1981.

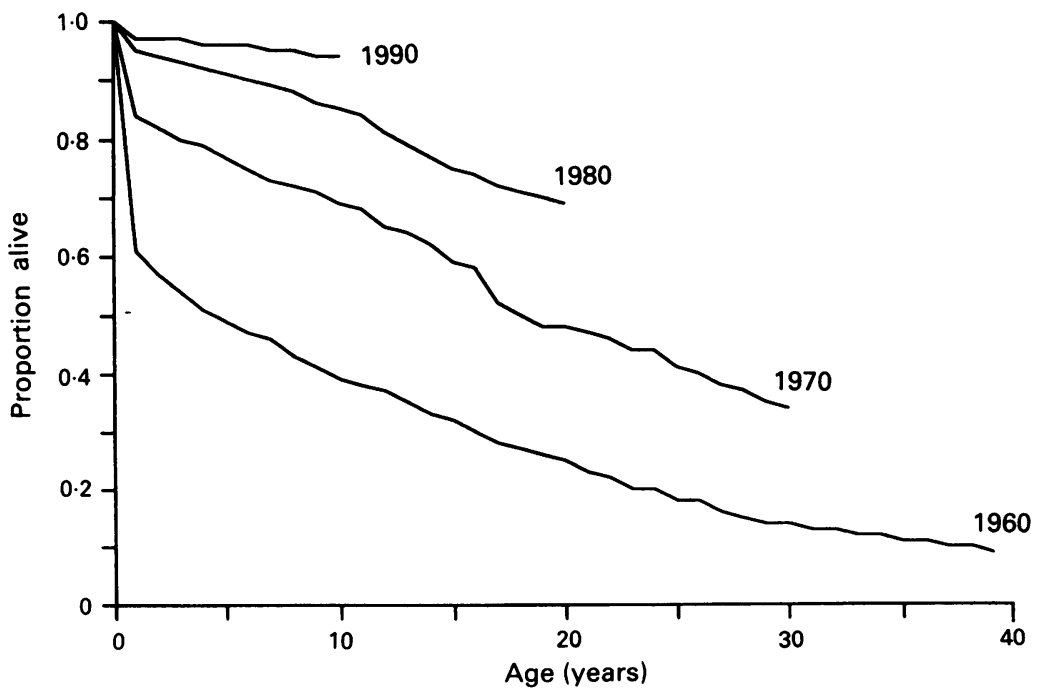

Figure 2 Survival curves for cohorts born at the beginning of each decade, extrapolated to the year 2000. (the increase in the logit for each year), and $b$ the logistic intercept (the proportion dying in 1959). This equation was then used to estimate the proportion of children dying in the first year of life for birth cohorts from 1987 to 2000 . As figures for live births were available only up to $1988^{16}$ (personal communication for 1988), we estimated that the number of annual live births for England and Wales from 1989 to 2000 would be approximately equal to the average for 1978-88 (635 187 births a year). From these estimates we calculated the number of children with cystic fibrosis born each year up to 2000 who would be expected to survive to their first birthday.

Mortality was then analysed for those surviving to their first birthday in each year of birth cohort by fitting a different logistic model, this time to the proportion dying each year within each cohort. In this model of $y=a x+b, y$ represents the logit of the proportion dying at age $x, a$ the increase in the logit for each year of age, and $b$ the logit of the proportion dying in the second year of life. We could not fit a reliable model to cohorts born after 1981 because there were few deaths and insufficient years of data, so mortality after the first year was predicted for each year of birth cohort, a model based on the trends for 1959-81 being used. The intercept of the logistic model for each cohort showed a progressive linear fall over the years 1959-81 (fig 1B) so we extrapolated this trend by least squares regression to provide intercepts for subsequent years. The gradient of the logistic equation did not show a pronounced trend with time from 1959 to 1981 , however (fig 1C), so we used the mean value for the gradient in the last five years of adequate data (1977-81) for subsequent cohorts.

The logistic model defined by this gradient and the extrapolated intercept for each year was then applied to the projected first year survivors from 1982 to 2000 and used to estimate the number of deaths for individuals born with cystic fibrosis until 2000 . These predictions were used to produce life tables for all annual cohorts from 1959 to 2000 and hence to estimate the size of the cystic fibrosis population for each year until the year 2000 .

\section{Results}

The proportion of patients dying in the first year of life declined substantially over the study period (fig 1A). A logistic model fitted this trend well, with a scaled residual deviance of 26.4 on 25 degrees of freedom. The least squares regression of the logistic intercept with time (fig 1B) was also a good description of the data, with an $r^{2}$ value of $0 \cdot 68$. Log transformation did not improve this fit. We elected to use the 1978-82 mean logistic gradient for future predictions because the least squares regrssion of this gradient against time did not differ significantly from zero (fig 1C) and because extrapolation of the logistic gradient along the weakly positive regression prediction produced implausible survival curves in which median survival fell after 1990. One final predictive model produced a series of survival curves, of which interval examples are shown in figure 2. Population 
Table 1 Number of live births and number of deaths during the first year of life and subsequent five year age bands by year of birth (actual births and deaths above the line, estimates from this study below the line; incomplete five year cohorts in parentheses)

\begin{tabular}{|c|c|c|c|c|c|c|c|c|c|c|}
\hline & \multirow{2}{*}{$\begin{array}{l}\text { No of children } \\
\text { born with } \\
\text { cystic fibrosis }\end{array}$} & \multicolumn{9}{|c|}{ No of deaths by year } \\
\hline & & $<1$ & $1-5$ & $6-10$ & $11-15$ & $16-20$ & $21-25$ & $26-30$ & $31-35$ & $>35$ \\
\hline $\begin{array}{l}1959 \\
1960 \\
1961\end{array}$ & $\begin{array}{l}300 \\
314 \\
325\end{array}$ & $\begin{array}{r}106 \\
122 \\
97\end{array}$ & $\begin{array}{l}38 \\
45 \\
54\end{array}$ & $\begin{array}{l}24 \\
29 \\
27\end{array}$ & $\begin{array}{l}15 \\
24 \\
26\end{array}$ & $\begin{array}{l}19 \\
21 \\
31\end{array}$ & $\begin{array}{r}9 \\
17 \\
25 \\
\end{array}$ & $\begin{array}{r}8 \\
10 \\
12\end{array}$ & $\begin{array}{l}5 \\
7 \\
9\end{array}$ & $\begin{array}{c}5 \\
5 \\
(6)\end{array}$ \\
\hline $\begin{array}{l}1962 \\
1963 \\
1964 \\
1965 \\
1966\end{array}$ & $\begin{array}{l}336 \\
342 \\
351 \\
346 \\
340\end{array}$ & $\begin{array}{r}107 \\
102 \\
86 \\
73 \\
78\end{array}$ & $\begin{array}{l}50 \\
46 \\
42 \\
33 \\
39\end{array}$ & $\begin{array}{l}27 \\
31 \\
34 \\
34 \\
31\end{array}$ & $\begin{array}{l}32 \\
32 \\
36 \\
29 \\
27\end{array}$ & $\begin{array}{l}28 \\
21 \\
31 \\
24 \\
23 \\
\end{array}$ & $\begin{array}{l}23 \\
18 \\
18 \\
17 \\
15\end{array}$ & $\begin{array}{l}12 \\
10 \\
18 \\
13 \\
14\end{array}$ & $\begin{array}{c}10 \\
8 \\
15 \\
11 \\
(9)\end{array}$ & $\begin{array}{l}(4) \\
(2) \\
(3)\end{array}$ \\
\hline $\begin{array}{l}1967 \\
1968 \\
1969 \\
1970 \\
1971\end{array}$ & $\begin{array}{l}333 \\
328 \\
320 \\
314 \\
314\end{array}$ & $\begin{array}{l}63 \\
74 \\
46 \\
50 \\
58\end{array}$ & $\begin{array}{l}37 \\
36 \\
27 \\
29 \\
30\end{array}$ & $\begin{array}{l}32 \\
35 \\
32 \\
23 \\
38\end{array}$ & $\begin{array}{l}30 \\
33 \\
29 \\
31 \\
31\end{array}$ & $\begin{array}{l}26 \\
39 \\
22 \\
24 \\
38\end{array}$ & $\begin{array}{l}18 \\
31 \\
26 \\
24 \\
36\end{array}$ & $\begin{array}{c}15 \\
27 \\
16 \\
23 \\
(26)\end{array}$ & $\begin{array}{l}(7) \\
(9) \\
(11)\end{array}$ & \\
\hline $\begin{array}{l}1972 \\
1973 \\
1974 \\
1975 \\
1976\end{array}$ & $\begin{array}{l}290 \\
271 \\
256 \\
242 \\
234\end{array}$ & $\begin{array}{l}41 \\
40 \\
29 \\
24 \\
23\end{array}$ & $\begin{array}{l}29 \\
14 \\
24 \\
28 \\
14\end{array}$ & $\begin{array}{l}31 \\
26 \\
23 \\
20 \\
22 \\
\end{array}$ & $\begin{array}{l}28 \\
20 \\
22 \\
15 \\
19\end{array}$ & $\begin{array}{l}22 \\
24 \\
22 \\
13 \\
29\end{array}$ & $\begin{array}{c}25 \\
25 \\
20 \\
10 \\
(24)\end{array}$ & $\begin{array}{r}(14) \\
(11) \\
(5)\end{array}$ & & \\
\hline $\begin{array}{l}1977 \\
1978 \\
1979 \\
1980 \\
1981\end{array}$ & $\begin{array}{l}228 \\
238 \\
255 \\
262 \\
254\end{array}$ & $\begin{array}{l}24 \\
20 \\
21 \\
10 \\
12\end{array}$ & $\begin{array}{r}16 \\
15 \\
12 \\
8 \\
15 \\
\end{array}$ & $\begin{array}{l}20 \\
13 \\
22 \\
13 \\
13\end{array}$ & $\begin{array}{l}26 \\
16 \\
42 \\
20 \\
18\end{array}$ & $\begin{array}{c}29 \\
16 \\
77 \\
26 \\
(18)\end{array}$ & $\begin{array}{l}(19) \\
(7) \\
(16)\end{array}$ & & & \\
\hline $\begin{array}{l}1982 \\
1983 \\
1984 \\
1985 \\
1986 \\
1987 \\
1988 \\
\end{array}$ & $\begin{array}{l}250 \\
252 \\
255 \\
262 \\
264 \\
273 \\
277 \\
\end{array}$ & $\begin{array}{r}10 \\
10 \\
7 \\
12 \\
4 \\
8 \\
6\end{array}$ & $\begin{array}{r}10 \\
7 \\
7 \\
5 \\
4 \\
4 \\
3\end{array}$ & $\begin{array}{r}12 \\
10 \\
11 \\
9 \\
7 \\
8 \\
5\end{array}$ & $\begin{array}{c}17 \\
15 \\
13 \\
11 \\
(8) \\
(6) \\
(3)\end{array}$ & $\begin{array}{l}(13) \\
(7) \\
(3)\end{array}$ & & & & \\
\hline $\begin{array}{l}1989 \\
1990 \\
1991 \\
1992 \\
1993 \\
1994 \\
1995 \\
1996 \\
1997 \\
1998 \\
1999 \\
2000\end{array}$ & $\begin{array}{l}253 \\
253 \\
253 \\
253 \\
253 \\
253 \\
253 \\
253 \\
253 \\
253 \\
253 \\
253\end{array}$ & $\begin{array}{l}6 \\
5 \\
5 \\
4 \\
4 \\
3 \\
3 \\
3 \\
2 \\
2 \\
2\end{array}$ & $\begin{array}{c}3 \\
3 \\
2 \\
2 \\
2 \\
2 \\
2 \\
(1) \\
(1) \\
(1)\end{array}$ & $\begin{array}{c}6 \\
5 \\
(4) \\
(2) \\
(1) \\
(1)\end{array}$ & (1) & & & & & \\
\hline
\end{tabular}

figures derived from these curves, amalgamated into five year age groups, are summarised in table 1.

From these data numbers of cystic fibrosis patients were estimated by year from 1980 to 2000 as the number of adults (aged 16 or over) and children (under 16 years, table 2, fig 3 ). A modest increase of only 133 children with cystic fibrosis $(4 \%)$ is predicted for England and Wales from 1990 to 2000, whereas the increase in the adult population will be of the order of $36 \%$ (676 individuals). The greatest increase in the adult population will occur in those over 25 years (from 517 to 1280 ).

Estimated median survival for cohorts born

Table 2 Estimated numbers of patients with cystic fibrosis in age bands of five years from 1980 to 2000 in England and Wales

\begin{tabular}{|c|c|c|c|c|c|c|c|c|c|}
\hline & \multicolumn{6}{|c|}{ Age (years) } & \multicolumn{3}{|l|}{ Totals } \\
\hline & $0-5$ & $6-10$ & $11-15$ & $16-20$ & $21-25$ & $>25$ & Children & Adults & All \\
\hline 1980 & 1084 & 986 & 911 & 608 & 158 & - & 2981 & 766 & 3747 \\
\hline 1985 & 1198 & 1008 & 853 & 769 & 520 & 113 & 3061 & 1422 & 4481 \\
\hline 1990 & 1273 & 1119 & 902 & 733 & 652 & 517 & 3294 & 1901 & 5196 \\
\hline 1995 & 4233 & 1196 & 948 & 770 & 611 & 961 & 3379 & 2342 & 5719 \\
\hline 2000 & 1244 & 1182 & 1001 & 701 & 596 & 1280 & 3427 & 2577 & 6004 \\
\hline
\end{tabular}

up to the present day are shown in figure 4. Children born in 1990 have a predicted median survival of 40 years.

\section{Discussion}

This study was conducted primarily to estimate the numbers of patients with cystic fibrosis by the end of the next decade, and to provide estimates of life expectancy for children with cystic fibrosis born now. We have used death certificate data from the Office of Population Censuses and Surveys as this is the most complete source of national mortality data available. Coding for cystic fibrosis deaths has changed on two occasions since 1959. For the years 1959-67 the International Classification of Diseases (ICD) Code was 587.2 and included other diseases of the pancreas. For these years the mortality from cystic fibrosis was adjusted by excluding deaths over the age of 50 years; we have previously argued that the adjustment is unlikely to have introduced any serious distortion into the estimates of number of deaths. ${ }^{14}$ From 1968 onwards an exclusive category for cystic fibrosis has been available so that little misclassification of reported deaths 


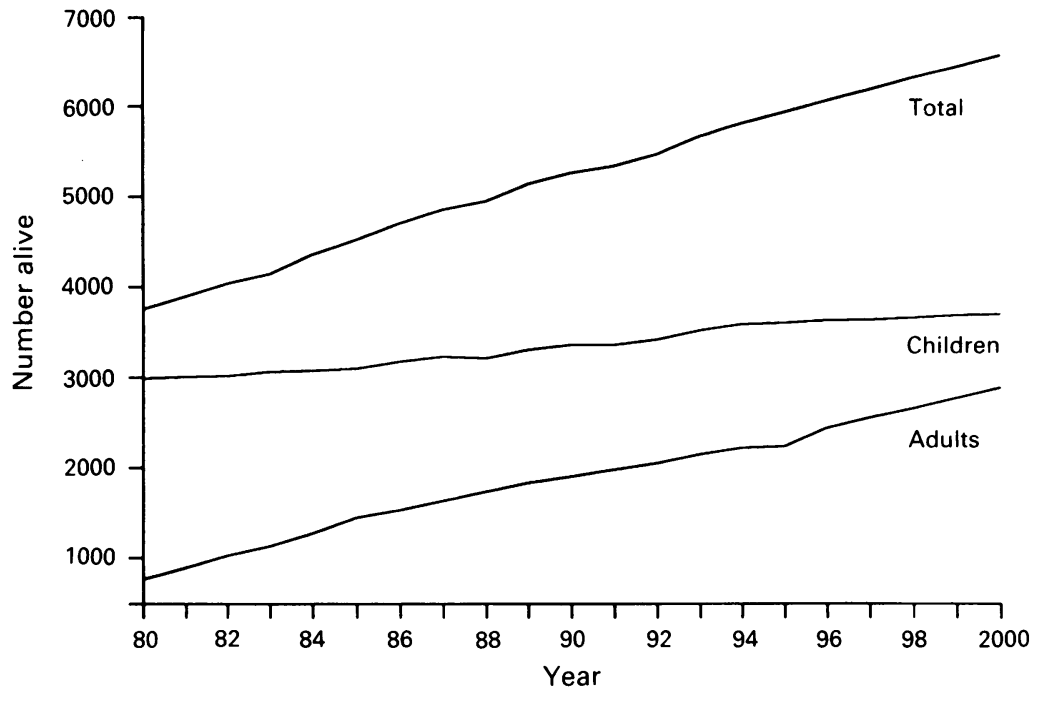

Figure 3 Estimated numbers of patients with cystic fibrosis by year from 1980 to 2000.

from cystic fibrosis is likely to have occurred since then.

We recognise that an unknown proportion of deaths of patients with cystic fibrosis will be classified under other causes and thus excluded from the survival calculations. Recent all cause mortality data show that the proportion of deaths from cystic fibrosis classified under other causes is currently very small $(4 \%$ of deaths due to cystic fibrosis in 1985 and 1986; personal communication, Office of Population Censuses and Surveys), but it is likely that some deaths from cystic fibrosis are unrecognised, that some have been recognised as being from cystic fibrosis but this diagnosis is excluded from the certificate, and that some patients have died from genuinely unconnected causes. The registered mortality by 27 years of age in the earlier cohorts, however, accounts for well over $70 \%$ of the expected number in each cohort, ${ }^{14}$ suggesting that the data are in fact reasonably complete even in the earlier years; with allowance for improvements in diagnosis and case ascertainment since the early 1960s the

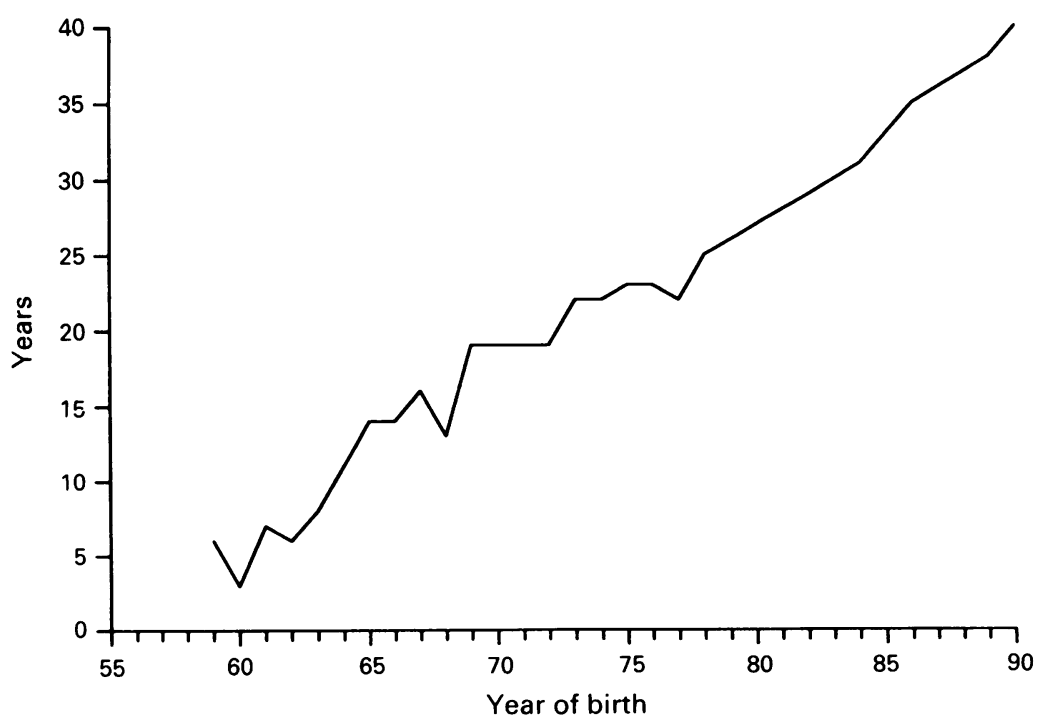

Figure 4 Median survival by year of birth from 1959 to 1990.
Table 3 Estimated numbers of patients with cystic fibrosis by region in 1990 and 2000

\begin{tabular}{|c|c|c|c|c|}
\hline \multirow[b]{3}{*}{ Region } & \multicolumn{4}{|c|}{ Age (years) } \\
\hline & \multicolumn{2}{|l|}{$<16$} & \multicolumn{2}{|l|}{$\geqslant 16$} \\
\hline & 1990 & 2000 & 1990 & 2000 \\
\hline NW Thames & 239 & 248 & 128 & 187 \\
\hline NE Thames & 261 & 271 & 150 & 204 \\
\hline SE Thames & 232 & 241 & 134 & 181 \\
\hline SW Thames & 180 & 187 & 104 & 141 \\
\hline Northern & 206 & 214 & 119 & 161 \\
\hline Yorkshire & 240 & 250 & 138 & 188 \\
\hline Trent & 299 & 312 & 188 & 234 \\
\hline East Anglia & 123 & 128 & 71 & 96 \\
\hline Wessex & 174 & 181 & 100 & 136 \\
\hline Oxford & 163 & 170 & 92 & 128 \\
\hline South West & 192 & 200 & 111 & 150 \\
\hline West Midlands & 354 & 369 & 205 & 277 \\
\hline Mersey & 165 & 172 & 95 & 129 \\
\hline North West & 277 & 288 & 160 & 217 \\
\hline Wales & 186 & 193 & 107 & 145 \\
\hline
\end{tabular}

cumulative effect of misclassification of deaths from cystic fibrosis is unlikely to be substantial.

The nature of the model used to predict numbers will obviously affect the survival estimates. We produced our model so far as possible from logical first principles and experimented in the process of the calculations with various predictive models. In the event the predictions for total numbers of adults and children were relatively robust to differences in the method of prediction, but median survival estimates were less stable. The model we adopted fitted the data well and produced live population estimates similar to those of an independent survey of prevalence by the British Paediatric Association Working Party on Cystic Fibrosis. For 1980 the British Paediatric Association's estimate of the total United Kingdom cystic fibrosis population was 4326 , which compares favourably with our estimate of 3747 for England and Wales alone. The accuracy of our estimate also depends on an assumption that there will be no major change in the live birth rate in the next decade. In fact, the number of live births has increased steadily over the past six years, ${ }^{16}$ and if this trend continues the number of young children with cystic fibrosis will exceed our estimates slightly.

A striking feature of our estimates is the $36 \%$ increase in adults with cystic fibrosis from 1990 to 2000 . As the magnitude of this increase was relatively robust to different prediction models we believe it to be reliable. This expansion in numbers will have implications for the provision of services for adult patients, which will have to grow to cope with this increase over the next 10 years. In contrast, the number of children with cystic fibrosis remains relatively constant, so current service provision may be sufficient. As deaths from cystic fibrosis will occur increasingly among adults morbidity is also likely to be greater in older patients. This will move the need for intensive inpatient care from the paediatic to the adult services, and make it likely that by the year 2000 the care of adults will require at least the same resources as those currently available for the care of children. To give an indication of the likely 
breakdown of population changes by regional health authority approximate numbers of patients were calculated by region on the basis of the proportional average live birth rate from 1978 to 1988; these are shown in table 3.

The increase in the cystic fibrosis population may be affected in future by the consequences of the recent discovery of the cystic fribrosis gene,${ }^{2021}$ which may lead to population screening $^{1112}$ and a reduction in the number of children born with cystic fibrosis. Widespread screening is unlikely before 1995 , however, and even if optimum uptake occurs a reduction in affected live births by only $40 \%$ has been suggested. ${ }^{12}$ This might have a small effect on the numbers of children born by 2000 , but will not effect the size of the adult population until well into the next century.

The prognosis for patients with cystic fibrosis has shown a progressive improvement over the past 30 years, and survival curves for England and Wales are similar to others based on populations in Europe ${ }^{722}$ and North America. ${ }^{15}$ The improvement in survival is likely to continue over the next decade with improved medical care and increased availability of heartlung transplantation. Our predictions of median survival for future cohorts were very sensitive to the model used, so we have reported our estimates only up to the present birth cohort. As these predictions are based on cumulative estimates from multiple birth cohort survival predictions they contain an element of error that is difficult to estimate. As there is so far no evidence that survival is plateauing, our current estimates are likely to be reasonably accurate. The relatively favourable outlook (compared with that of 30 years ago) for a child born in 1990 with cystic fibrosis should allow reasonably optimistic advice to be given to parents. The current median age of death in England and Wales is of the order of 20 years, ${ }^{14}$ and advice based on these figures will be unduly pessimistic. The continuing improvement in prognosis also raises questions about the acceptability of population and prenatal screening, ${ }^{23}$ as many couples are likely to question the morality of an abortion when a child born with cystic fibrosis may have a median survival of the order of 40 years. ${ }^{11}$ It may also be difficult to justify expensive population screening for a disease with such a prognosis, ${ }^{11}$ given that many adults with cystic fibrosis enjoy a good quality of life and contribute to society economically and socially. ${ }^{24}$ We believe that our figures provide grounds for some optimism for those concerned with the care of patients with cystic fibrosis and with counselling parents of children born recently with cystic fibrosis, parents of a fetus likely to be affected by cystic fibrosis, and young patients with the disease.

J S E is supported by the Cystic Fibrosis Research Trust. We also thank Richard Somerville and Nirupha Lakhani from the Office of Population Censuses and Surveys for supplying the raw data and Jim Pearson for additional statistical advice.

1 Warwick WJ, Pogue RE, Gerber HU, Nesbitt CJ. Surviva patterns in cystic fibrosis. J Chron Dis 1975;28:609-22.

2 Anonymous. Survival in cystic fibrosis [editorial]. Lancet 1984;ii:663-4

3 David TJ. Cystic fibrosis. Arch Dis Child 190;65:152-7.

4 Corey M, McLaughlin FJ, Williams M, Levison H. A comparison of survival, growth and pulmonary function in patients with cystic fibrosis in Boston and Toronto. J Clin Epidemiol 1988;41:583-91.

5 Huang NN, Macri CN, Girone J, Sproul A. Survival of patients with cystic fibrosis. Med J Aust 1970;120:289-95.

6 Phelan PD, Allan JL, Landau LI, Barnes GL. Improved survival of patients with cystic fibrosis. Med J Aust 1979; i:261-3.

7 Nielsen OH, Schoitz PO. Cystic fibrosis in Denmark in the period 1945-1981. Evaluation of centralised treatment. period 1945-1981. Evaluation of centralised
Acta Paediatr Scand 1982; supple 301:107-19.

8 British Thoracic Society. Report on the organisation of care for adult patients with cystic fibrosis. British Thoracic Society News 1989;4:6-10.

9 Dodge JA. Implications of the new genetics for screening for cystic fibrosis. Lancet ii:672-4.

10 Lemna WK, Feldman GL, Karem BS, et al. Mutation analysis for heterozygote detection in the prenatal diag nosis of cystic fibrosis. N Engl J Med 1990;322:291-6.

11 Colten HR. Screening for cystic fibrosis. $N$ Engl J Med 1990;322:328-9.

12 Anonymous. Cystic fibrosis: prospects for screening and therapy. Lancet 1990;i:79-80

13 Ten-Kate LP, Tijmstra TJ. Carrier screening for cystic fibrosis. Lancet 1989;ii:973-4.

14 Britton JR. Effects of social class, sex and region of residence on age at death from cystic fibrosis. $B M J 1989 ; 298: 482-6$. 15 Office of Population Censuses and Surveys. Birth statistic 1976. London: HMSO, 1978. (Series FMI No 2.)

16 Office of Population Censuses and Surveys. Birth statistics 1987. London: HMSO, 1989. (Series FMI No 2.)

17 Dodge JA. Cystic Fibrosis in the United Kingdom 1977-85. an improving picture. $B M J 1988 ; 297: 1599-602$.

18 SPSS-X. SPSS-X users guide. 2nd ed. New York: McGraw Hill, 1986.

19 Numerical Algorithms Group. The generalised linear interactive modelling system. Release 3.77. Oxford: Royal Statistical Society, 1986.

20 Rommens JM, Ianuzzi MC, Karem B-S, et al. Identification of the cystic fibrosis gene: chromosome walking and jumping. Science 1989;245:1059-65.

21 Riordan JR, Rommens JM, Karem B-S, et al. Identification of the cystic fibrosis gene: cloning and characterisation of complementary DNA. Science 1989;245:1066-73.

22 Kollberg $H$. Incidence and survival curves for cystic fibrosis. Acta Paediatr Scand 1982;71:197-202.

23 Knight RA, Hodson ME. Identification of the cystic fibrosis gene. $B M J$ 1990;300:345-6.

24 Batten JC. The adolescent and adult. In: Hodson ME Batten JC, eds. Cystic fibrosis. Oxford: Ballière Tindall, 1983. 
Juniors, whether preparing for an audit meeting or revising for the Intercollegiate examination, will find it indispensable. This book should certainly be found in the library of every department of cardiac and thoracic surgery.-JHD

Lecture Notes on Respiratory Disease. 4th ed. R A L Brewis. (Pp 317; £12.95.) Oxford: Blackwell, 1991. ISBN 0-63202777-0.

This book, which is a member of the popular "Lecture Notes" series, has been written as a concise introductory text to the essentials of respiratory medicine. It is into its fourth edition and there has been an obvious effort to keep the text up to date. The book is structured in a standard format. The first section discusses aspects of lung structure and function, and includes a clearly written review of respiratory physiology with effective use of models to explain some difficult concepts. This is followed by a section that focuses on diagnostic techniques. Chest radiology forms an integral part of respiratory medicine, and the author has provided a useful, simple description of the elements of chest radiographs as well as of computer tomograms of the thorax. The emphasis of this book is on practical aspects of the more common respiratory problems seen in clinical medicine and some new chapters have been added here, including chapters introducing the rapidly expanding areas of respiratory disease in patients with AIDS and the immunocompromised and of ventilatory failure and sleep apnoea. I was disappointed that there was not more discussion of the pharmacology of drugs used in the treatment of some respiratory disorders and perhaps a larger section on assisted ventilation. In addition, there are occasional irritating typesetting errors. Overall, however, this book is very well written in an easy to read, concise style and it is supplemented by many excellent illustrations. It has been primarily aimed at the medical student but it would also be a useful reference for the junior hospital doctor and the MRCP candidate. Priced at $£ 12.95$ it is good value for money.-CW

Atlas of Rare Chest Diseases in Children. J Rudnik, R Kurzawa. (Pp 192; no price given.) Rabka, Poland: National Research Institute of Mother and Child, 1991. ISBN 83-00-03293-2.

This atlas contains 56 reports of rarities, largely from the National Research Institute of Mother and Child in Rabka, Poland. I envy them their 640 beds for paediatric respiratory medicine and their wealth of clinical material. Clearly the investigative facilities as revealed here are not fully up to modern standards. The computed tomograms are scanty and there are no nuclear magnetic resonance images. In consequence, bronchography is performed far more often than in Western Europe. The planning of each report is good, and there are some interesting cases; there is a presentation, imaging studies, and pathological material. The illustrations are copious but tend to be poorly reproduced; and it is not easy to get used to reversed radiographs (black bones, white air). Latin is overused ("compressio trachea post destropositionem arteriae pulmonalis sinistrae" does not often trip off the tongue in my hospital). Unfortunately, no attempt is made to use these fascinomas to illustrate general principles. There is no mention of paediatric HIV. The use of fibreoptic bronchoscopy and transbronchial biopsy is not explored. The references are grouped alphabetically at the end of the book, rather than being attached to the case report to which they refer, and some are incomplete and outdated. But this is a very impressive attempt at producing a text of fascinating problems with limited funding and facilities. The authors are to be congratulated on their enterprise. This is mainly a book for the medical historian, possibly a book to skim but not one to buy for yourself.-AB

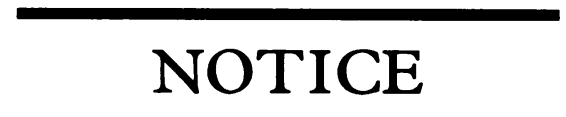

British Society for Allergy and Clinical Immunology conference

The society's 1992 annual conference will be held on 7-9 September at the University of Southampton. Further information from Amanda Barber, Conference Associates and Services Ltd, BSACI 1992, Congress House, 55 New Cavendish Street, London W1M 7RE (tel 071486 0531, fax 071935 7559).

\section{CORRECTION} Cystic fibrosis: current survival and
population estimates to the year 2000

In the paper by JS Elborn et al (December $1991 ; 46: 881$ ) the address for reprint requests should be: Section of Respiratory Medicine, University of Wales College of Medicine, Llandough Hospital, Penarth, South Glamorgan CF6 1XX. 